\title{
Desenho do trabalho e patologia organizacional: um estudo de caso no serviço público
}

\author{
José Marcal Jackson FiLHo \\ FUNDACENTRO/SC \\ E-mail:marcal@fundacentro.sc.gov.br
}

\begin{abstract}
Resumo
A noção "patologia organizacional" parece propícia para descrever a precariedade do funcionamento do setor público e explicar o adoecimento dos servidores. Neste trabalho, baseado em estudo de caso em uma instituição pública, o funcionamento organizacional, suas conseqüências e o processo social de desenho do trabalho são descritos. Mostra-se que: o serviço apresenta características nítidas de "organização patológica", isto é, alta prevalência de problemas músculo-esqueléticos, funcionamento precário e pouca margem de ação da direção local; os problemas de funcionamento estão associados à fragilidade do processo de desenho do trabalho, caracterizado pela falta de competências em gestão da produção, inexistência de serviços de apoio Corganização e métodos, arquitetura, etc. J, pouca margem para contratações. Como muitas instituições apresentam problemas semelhantes, conclui-se que, caso o governo brasileiro pretenda se contrapor ao processo histórico de precarização dos serviços prestados aos cidadãos, ele deve re-conceber o desenho do trabalho e as estruturas disponíveis nas instituições públicas.
\end{abstract}

\section{Palavras-chave}

Organização, serviço público, patologia organizacional, desenho do trabalho, adoecimento.

\section{Work design and "sick workplace syndrome": a case study in a public institution}

\begin{abstract}
The notion of "sick workplace syndrome" is appropriate to describe the poor working conditions of many public organizations and to explain the health problems of public workers. In this paper, a case study in a public institution was carried out; its organization and its work design process were described. The results show that: this Public Institution "suffers from" a "sick workplace syndrome", i.e., there are a high prevalence of musculo-skeletal disorders, many organizational failings and lack of control by local managers; the organizational problems are associated to the limitations of the work design process due to the lack of knowledge in industrial engineering and public administration, lack of support by specific design services and small latitude to hire new workers.
\end{abstract}

Key words

Organization, public sector, "sick workplace syndrome", work design, occupational illness. 


\section{INTRODUĈ̣̃O}

Para abordar a problemática das relações entre Organização do Trabalho e Psiquismo Humano, trataremos neste artigo da influência dos modos de organização sobre o adoecimento dos trabalhadores do setor público.

Os efeitos das formas de organização do trabalho sobre o funcionamento psíquico dos trabalhadores de vários setores são objeto de vários estudos no campo da Psicodinâmica do Trabalho (DEJOURS, 2000). Diversos estudos de natureza epidemiológica têm mostrado associações entre fatores de risco organizacionais (ou psicosociais) e o adoecimento mental (MUNTANDER e EATON, 1998), músculoesquelético (LIM, SAUTER e SWANSON, 1998) e até cardiovascular (THEOREL e JOHNSON, 1998) dos trabalhadores de vários setores.

Além disso, assiste-se, atualmente, a processo de intensificação do trabalho e à introdução de diferentes formas de racionalização, que decorrem da re-estruturação produtiva e da economia (WINKEL e WESTGARD, 2001). A maior intensidade do trabalho, que se materializa através de maior ritmo imposto de trabalho, menos tempo para pausas, maior pressão das chefias e diferentes formas de intimidação, está associada ao aumento da prevalência dos problemas de saúde dos trabalhadores (HAMON-CHOLET e ROUGERIE, 2000; DAUBASLETOURNEUX e THÉBAUD-MONY, 2002).

No entanto, a reflexão sobre situações de trabalho com alta prevalência de trabalhadores doentes mostra que o próprio serviço ou setor também sofre de certa "patologia organizacional" (DANIELLOU, 1999). Nesses casos, podem ser encontradas fontes de perda de produtividade não detectadas pela empresa e que agravam a situação dos trabalhadores.

A noção "patologia organizacional" parece, de um lado, bem propícia para descrever o funcionamento dos serviços do setor público. De certa forma, o serviço público no Brasil tem sofrido desse "mal" de forma crônica e a "desmotivação" do servidor público pode ser outra forma de expressão ("sintoma") de patologia organizacional. Por outro lado, toda organização resulta do trabalho de determinados atores internos ou externos ao conjunto da empresa (CARBALLEDA, 2002), distribuídos em determinados setores dos órgãos públicos ou das empresas (organização e métodos, engenharia, qualidade, etc.), ou ocupando cargos de chefia. Assim, a descrição do processo social de desenho do trabalho e da organização é fase fundamental para a compreensão das formas "patológicas" e de suas "fontes geradoras", e para transformar o próprio processo de desenho do trabalho.

Partindo do pressuposto que o atual governo pretende melhorar o funcionamento da prestação dos serviços aos cidadãos, baseados nos princípios que lhe são próprios eqüidade, justiça -, é objetivo deste artigo, a partir da reflexão sobre o estudo de um caso, descrever os problemas de funcionamento de uma instituição e o processo social de desenho organizacional (e do trabalho), para discutir sobre a necessidade de re-conceber tal processo de forma ampla (sua estrutura, atores e referencial teóricometodológico).

\section{PREVALÊNCIA DE LER/DORT, PATOLOGIA ORGANIZACIONAL NOS SERVICOOS PÚBLICOS E PROCESSO SOCIAL DE DESENHO ORGANIZACIONAL}

O governo federal admite a relação entre adoecimento dos servidores públicos e suas condições de trabalho, ao afirmar publicamente que $24,7 \%$ das aposentadorias de servidores se devem a problemas de saúde decorrentes do trabalho ${ }^{1}$.

A precariedade das condições de trabalho, caracterizada por meios e equipamentos insuficientes e inadequados, espaços mal desenhados, práticas gerenciais distantes da realidade, dentre outros, tem sido descrita em vários estudos [por exemplo, ASSUNÇÃO (1998), JACKSON e BARCELOS (1999) e SOUZA e MINAYO (2003)], interessados pelo desempenho dos trabalhadores que atendem os cidadãos nos órgãos públicos.

Além disso, o setor público submete-se, assim como o setor privado, a processo de intensificação do trabalho e a diferentes formas de racionalização. Dentro desse contexto difícil, atuam os servidores públicos, pressionados, também, por cidadãos mais conscientes de seus direitos (CHAUVIÈRE e GODBOUT, 1992) e impacientes com a "ineficiência" do funcionamento dos serviços (saúde, segurança pública, justiça).

Assiste-se, por isso, à introdução, na tentativa de "reforma da gestão pública" (SKALEN, 2004), de métodos e de ferramentas de gestão utilizados no setor privado, visando aumentar a eficácia da prestação dos serviços públicos. No entanto, eles nem sempre estão adequados à realidade de funcionamento (RAVEYERE e UGHETO, 2002) e não atingem, necessariamente, os resultados esperados (SKALEN, 2004).

Deve-se ressaltar que, no caso brasileiro, a adoção de tais medidas pelo governo anterior, guiadas pela racionalidade econômica predominante, não visava necessariamente melhorar a prestação de serviços, mas, ao contrário, seu móbile principal era reduzir o papel do Estado (OLIVEIRA, 1999).

Nesse quadro, não haveria forte associação entre o adoecimento dos servidores e a degradação do funcionamento dos serviços públicos? Ou em outras palavras, a 
prevalência de LER/DORT não seria sintoma de "patologia organizacional”, como propõe Daniellou (1999)?

\section{Patologia Organizacional}

Daniellou (1999) propõe a expressão "patologia organizacional" ao refletir sobre intervenções de natureza ergonômica no enfrentamento de situações de trabalho contendo alta prevalência de problemas músculoesqueléticos ${ }^{2}$.

Afirma que, nessas situações, não somente os trabalhadores sofrem, mas, também, os funcionários da hierarquia intermediária e os membros da administração do estabelecimento.

De um lado, os trabalhadores da hierarquia intermediária sofrem, pois são submetidos pela empresa a injunções implícitas do tipo "tendo ou não vassoura, varra de qualquer jeito"; "isto quer dizer que são levados a difundir, no sentido descendente, as mensagens vindas da direção, sem possibilidade de transmitir, no sentido ascendente, as dificuldades encontradas no cotidiano, para que soluções sejam estudadas no médio prazo" (p. 34). De outro lado, os membros da administração sentem-se impotentes para mudar a situação, pois têm pouca margem de manobra para enfrentá-la.

Nota-se, nelas, funcionamento paradoxal caracterizado por:

1) "Fonte de perda de produtividade não detectada pela empresa";

2) Tentativa de compensação dessa perda de produtividade através de pressão direta sobre os ritmos de trabalho ou sobre os efetivos;

3) Agravação da perda de produtividade devida aos efeitos secundários dessa pressão" (p.36).

Além dos "sintomas" enunciados acima, seja a alta prevalência de problemas músculo-esqueléticos, seja o funcionamento precário e pouco eficiente, a deterioração das relações no trabalho [formas de estresse relacional (WELLER, 2002)] surge como outro sintoma de "organizações doentes".

Enfim, "pode-se associar as situações geradoras de problemas músculo-esqueléticos a uma síndrome geral de sentimento de impotência". (p. 34; em negrito pelo autor)

Daniellou destaca a situação dos dirigentes de fábrica que enfrentam problemas de LER/DORT nas suas dependências. Segundo ele, os dirigentes possuem pouca margem de ação, pois sua fábrica depende de um cliente principal ou único, ou pertence à empresa multinacional (cujo processo decisório encontra-se distante) e ou atua em setor de forte concorrência mundial. Pode-se inferir que a capacidade de re-desenho organizacional, em sentido amplo, está comprometida.
Como sair desse impasse? O autor argumenta a importância de incluir a dimensão "política", isto é, a vontade relativa ao futuro, no processo de transformação da situação. Assim, para enfrentar a prevalência de LER/DORT na empresa, é preciso considerá-la como questão estratégica, isto é, como desafio para a sobrevivência da empresa (ou da fábrica) e não apenas tratá-la do ponto de vista estritamente técnico ou médico.

Embora Daniellou tenha feito referência ao setor privado (em especial, industrial), suas considerações sobre a caracterização de situações de "patologia organizacional" e sobre seu enfrentamento merecem ser consideradas para o entendimento e transformação do funcionamento dos serviços públicos.

\section{Relação entre o adoecimento e as características do desenho organizacional e do trabalho no serviço público}

A alta prevalência de problemas músculo-esqueléticos compromete o funcionamento dos serviços públicos. Ela indica, em primeiro lugar, certa crise no desenho e desenvolvimento de políticas públicas. Em segundo, aponta para a insuficiência do processo social institucionalizado de desenho organizacional e do trabalho.

Sabe-se que as instituições públicas não possuem nem estruturas formais de desenho da organização e do trabalho nem setores de apoio à "produção de serviço", como "qualidade, marketing, engenharia de processo, organização e métodos, dentre outros".

Por outro lado, o referencial teórico-metodológico utilizado é insuficiente: o desenho das organizações e das tarefas necessárias é feito, em muitos casos, sem várias informações e conhecimentos fundamentais e por profissionais sem qualificação em administração pública ou engenharia de produção. Na maioria das vezes, os "projetistas" (chefias, em geral) desconhecem as atividades efetivamente realizadas pelos servidores e acabam por desconsiderar elementos essenciais para o projeto da nova organização (GUERIN et al., 2001). São deixados de lado aspectos importantes, também, pois não são empregados métodos participativos na condução de projetos técnico-organizacionais (DUARTE, 2002).

Para suprir essa insuficiência, assiste-se à importação de modelos e técnicas usadas no setor privado, sem a devida reflexão sobre sua aplicabilidade no funcionamento dos serviços públicos (RAVEYRE e UGHETO, 2002). A organização que resulta desse processo social não é, na maioria dos casos, suporte conveniente para as atividades dos servidores (RAVEYRE e UGHETO, 2002), mas acaba impedindo ou dificultando a realização dos serviços para os cidadãos. Embora o objetivo do 
processo social não seja explicitamente o de impedir as atividades dos trabalhadores, como no caso das atividades de teleatendimento (SZNELWAR e ARBIX, 2003), o impedimento ao trabalho devido à falta de meios materiais e de estrutura (por exemplo, JACKSON e BARCELOS, 1999), isto é, devido à existência de exigências contraditórias entre objetivos e meios disponíveis, provoca a perda de sentido do "trabalhar" e o sofrimento físico, psíquico e moral (HAMON-CHOLET e ROUGERIE, 2000).

\section{ESTUDO DE CASO}

A descrição apresentada adiante resulta de parte de estudo ergonômico realizado em instituição pública que, por motivos confidenciais, será denominada de Agência Governamental de Proteção aos Cidadãos (AGPC). Pretende-se, nesta parte do texto, analisar e descrever a organização de uma divisão dessa Agência e o processo social do desenho do trabalho e da organização.

\section{Métodos}

Análise Ergonômica do Trabalho (AET) (GUERIN et al., 2001) foi realizada para compreender a prevalência de casos de problemas músculoesqueléticos no Setor de Apoio da Divisão de Defesa dos Direitos (DDD).

Não serão apresentados, neste texto, os resultados completos da AET, mas somente a análise realizada do funcionamento da organização da DDD e do processo social de desenho do trabalho e da organização.

Os métodos utilizados foram: entrevistas com servidores e agentes do Estado, análise de documentos e observações no local de trabalho.

\section{Do papel e das características da AGPC}

A AGPC é instituição de papel relevante na proteção aos cidadãos e a seus direitos. Ela possui direção central em Brasília e várias unidades nos diferentes Estados. Todas as unidades são compostas de algumas divisões, dentre elas, a Divisão de Defesa dos Direitos (DDD).

Os Agentes de Estado (AE) têm atribuições regidas por lei específica distinta da dos servidores administrativos das várias divisões e setores. São autoridades que representam o Estado Brasileiro e, para tal, desenvolvem uma gama de atividades, sustentadas pelo poder de envolver outras instituições governamentais em suas ações. Possuem total liberdade de ação, não são sujeitos a hierarquia, o que torna muito complexa e particular a organização da agência.

Nesta unidade da AGPC, um AE assume a direção geral, através de processo de votação interna, tendo como atribuição a gestão administrativa. Nela, os AEs atuavam nas várias divisões, pertencendo a cada divisão por período determinado e, em seguida, passando a fazer parte da equipe das demais. A DDD é a divisão responsável por assegurar os direitos dos cidadãos.

Dezesseis AEs compõem a equipe da DDD, divididos em quatro áreas específicas de atuação. A equipe elege anualmente um grupo de coordenação (um coordenador e dois vice-coordenadores), cujo papel é administrar o funcionamento do Setor de Apoio.

\section{0 paradoxo da alta prevalência de LER/DORT entre os servidores}

A alta prevalência de LER/DORT na Agência, em especial na DDD, que deu origem ao estudo ergonômico realizado, provocou grande desconforto na direção e em muitos AEs.

Em primeiro lugar, o problema das LER/DORT remetia à dimensão simbólica, ou seja, à própria imagem da Instituição. Não parecia aceitável para vários AEs saber que, para proteger os cidadãos, o funcionamento da Agência estava associado ao adoecimento de outros cidadãos, isto é, seus servidores.

\section{entro desse contexto difícil, atuam os servidores públicos, pressionados, também, por cidadãos mais conscientes de seus direitos}

Em segundo lugar, o adoecimento importante de servidores, que era, ao mesmo tempo, resultante do modo de organização e de funcionamento da divisão, era fator determinante para o funcionamento precário, comprometendo a prestação de serviços à sociedade e limitando a capacidade de atuação da Agência.

Evolução das demandas e da produção de serviços

A Agência produzia "estatísticas" das demandas recebidas e da produção de serviços realizados. O principal objetivo era disponibilizar dados da atuação da Agência ao público e à direção em Brasília para "prestar contas" à sociedade.

Pode-se observar, na Tabela 1, que houve crescimento da produção, observado através do número de acordos e de audiências realizadas, entre 1997 a 2002, com pequena redução em 2001. Com relação à demanda, houve crescimento entre 1997 e 2000 e redução entre 2000 e 2002. 
Não havia, todavia, instrumento de gestão disponível para coordenar ações e para avaliar medidas visando melhorar o desempenho da Agência: a análise dessas "estatísticas" não era feita para re-interrogar o funcionamento dos serviços, mas, como dito acima, para justificar o papel da instituição.

\section{Atribuições do Setor de Apoio à DDD}

$\mathrm{O}$ setor tem três funções principais: a primeira função é "secretariar" as atividades dos dezesseis agentes de estado, isto é, atendê-los, encaminhar-lhes os documentos, juntar documentos aos processos em curso, redigir e enviar ofícios, requerimentos e convocações, secretariar reuniões; a segunda consiste em "proteger" os processos em andamento e em acompanhamento, controlando sua localização no espaço da AGPC; a terceira função é atender os cidadãos ou seus representantes que buscam informações sobre processos.

\section{A evolução das formas de organização do Setor de Apoio}

O grande aumento da demanda da atuação na DDD nos últimos cinco anos (considerando de 1997 a 2002) foi acompanhado pelo crescimento do número de servidores e de AEs: o número de AEs aumentou de 6 em 1997, para 10 em 1998 e16 em 2000 (número atual de AEs) e o número de servidores passou de 9 em 1997 para 21 em 2003 (2 deles encontravam-se em licença médica). É importante notar que o aumento de servidores não ocorreu na mesma proporção que o aumento de AEs!

Vários modos de organização foram introduzidos, visando maior efetividade do serviço ${ }^{3}$.

Desde 1997, três modos de organização foram adotados:

a) Um servidor secretariando de forma exclusiva a um AE, modo que vigorou até o ano de 2000.

b) A partir de 2000, foi instituído o modo cartorial, com a criação de três ofícios; os dezesseis servidores dividiram-se nos três ofícios, além de três servidores na secretaria. Cada ofício passou a ocupar espaço distinto. Segundo alguns servidores, esse modo de organização foi considerado o mais "duro", sob o ponto de vista das condições de trabalho, pois as faltas de um colega sobrecarregavam os demais.

c) Em 2001, novo modo de organização foi implantado, que perdurou até 2003. O modo de organização baseou-se na divisão dos servidores em 4 setores especializados: coordenação, contando com 2 servidores; controle/protocolo, com 3; atendimento, com 4; e execução, 12. Segundo um AE, essa organização "taylorista", pois foi baseada na divisão de tarefas, foi o único modo possível encontrado para responder à demanda por serviços. Na implantação dessa organização, o setor foi posicionado em espaço único em outro andar da Agência.

\section{Características e problemas do funcionamento por grupos especializados}

\section{Princípio de funcionamento e capacidade do setor}

Toda demanda apresentada, dentro do campo de atuação da AGPC, era analisada pela DDD; a necessidade de assegurar os direitos dos cidadãos se constitui no princípio fundador do seu funcionamento. Contudo, apesar de não serem conhecidos os limites do Setor de Apoio, sua capacidade de atendimento mostrou-se próxima do limite.

Como resultado da grande demanda social, os servidores passaram a conviver com grande quantidade de trabalho. Cada falta, período de férias ou licença prolongada eram problemáticos para a chefia e colegas. Formaramse freqüentes mutirões para evitar o acúmulo de trabalho no setor, como os ocorridos em junho de 2002 ou em novembro de 2002.

Outro problema residia na dificuldade de distribuir de forma balanceada as tarefas para cada servidor, pois cada um, dentro de sua especialidade, atendia um grupo de AEs e cada AE possuía estilo próprio de trabalho, exigindo mais ou menos dos servidores. Além disso, as mudanças de AEs implicavam para os servidores aprender novas formas de trabalho, com isso variando suas cargas de trabalho.

\section{Natureza do trabalho e qualificação requerida}

Dos 21 servidores da DDD, 10 possuíam cargo de nível superior ( 2 deles estavam em licença médica) e 11 eram de nível técnico. Não havia no serviço, no entanto, tarefas que exigissem necessariamente qualificação de nível superior.

As tarefas realizadas pelos servidores, embora envolvessem muita responsabilidade, eram na sua maioria

Tabela 1: Evolução da demanda e do número de audiências e acordos firmados.

\begin{tabular}{|l|r|r|r|r|r|r|}
\hline & 1997 & 1998 & 1999 & 2000 & 2001 & 2002 \\
\hline Demandas recebidas & 555 & 1.456 & 1.892 & 2.598 & 1.883 & 1.838 \\
\hline Audiências realizadas na Agência & 443 & 967 & 1.364 & 1.571 & 1.264 & 1.908 \\
\hline Acordos firmados & 53 & 283 & 465 & 507 & 479 & 596 \\
\hline
\end{tabular}


monótonas e repetitivas - juntar documentos, numerar processos, redigir ofícios e convocações ou marcar reuniões, etc. Uma servidora do atendimento, ao descrever suas atividades, disse: "quando preciso conferir linha a linha deste formulário, sinto-me como uma 'caixa' de supermercados".

De outro lado, eram obrigados a considerar vários pormenores relativos a datas, pessoas, endereços, nos documentos a serem juntados ou nas ordens recebidas. Além disso, trabalhavam sob pressão, pois qualquer erro poderia significar advertência, e até processo administrativo. Por exemplo, uma servidora fora repreendida por cometer erro na numeração das páginas de um processo. Outra servidora se expressou, com relação à situação vivida por sua colega: "tudo isso é uma fobia"!

Segundo alguns servidores, os de nível superior ingressaram no setor para melhorar o atendimento aos AEs, na época em que cada servidor atendia a um AE. Com o aumento da demanda por serviços, coube a eles realizar apenas tarefas básicas de apoio aos AEs, o que aumentou sobremaneira o "custo (de produção)" dos serviços prestados e causou grande desmotivação entre eles.

\section{Lógica de eficácia individual}

Diante da limitação da capacidade de atendimento do Setor de Apoio, para poder cumprir seu papel e obter melhores resultados em seus procedimentos, cada AE se empenhava, a sua maneira, em influenciar o funcionamento do setor. De certa forma, cada AE baseava-se em lógica de eficácia individual, contrariando, em determinadas situações, algumas regras e modos de funcionamento estabelecidos no serviço para atender de forma eqüitativa a todos os AEs.

Algumas situações recorrentes ilustram esta contradição:

- Embora houvesse modelos de documentos disponíveis, no sistema de informática, alguns AEs exigiam dos servidores redação própria para seus documentos.

- A despeito do sistema de escala de servidores para secretariar reuniões, alguns AEs solicitavam junto à chefia do serviço os préstimos de servidores preferidos.

\section{O trabalho da chefia do Setor de Apoio}

O trabalho da chefia do setor era fundamental para tentar dividir melhor a quantidade de trabalho entre os servidores e para mobilizá-los ante a necessidade de realizar mutirões. Tinha também papel fundamental no gerenciamento de conflitos entre servidores, e entre servidores e AEs. Sua carga de trabalho era enorme, pois, além das tarefas supracitadas, realizava séries de tarefas "técnicas".
Entretanto, embora realizasse grandes esforços, seu trabalho refletia o tipo de organização do Setor de Apoio: organização voltada ao curto prazo. Sua afirmação, "apagando fogo", mostrava suas dificuldades em elaborar planejamento organizacional capaz de tornar mais efetivo o funcionamento da secretaria.

Além disso, a servidora-chefe estava submetida, por vezes, a injunções contraditórias. Em algumas situações precisava tentar convencer o grupo de AEs e a administração da Agência que determinada medida, na iminência de ser tomada, poderia dificultar ainda mais o funcionamento da secretaria. Sua dificuldade maior residia no desconhecimento, por parte de alguns AEs, da realidade do funcionamento do serviço e, sobretudo, de seus problemas.

\section{A s próprias atividades dos AEs estavam se reduzindo às possibilidades e à capacidade de atendimento do setor}

Por exemplo, em dada ocasião, a Agência dispunha de orçamento para comprar novos mobiliários. A coordenadora (AE) da DDD pretendia comprar células de trabalho com divisórias elevadas para impedir as conversas entre os servidores e sua desatenção. A servidora-chefe, no entanto, tinha receio quanto às consequiências possíveis dessa escolha, pois, de um lado, as conversas eram interações necessárias ao trabalho, sendo fundamentais para dirimir dúvidas relativas aos processos e procedimentos e, por outro lado, eram meio para amenizar o "clima pesado" no setor.

Nesses períodos de "negociação", percebia-se que a servidora-chefe sofria devido ao isolamento em que se encontrava (muitas informações eram consideradas confidenciais) e devido ao "temor" ante as dificuldades futuras, caso as ditas medidas fossem tomadas. Sua posição era extremamente frágil.

\section{As conseqüências desse funcionamento: os sintomas da patologia organizacional}

\section{Problemas de saúde e desmotivação dos servidores}

A ocorrência de casos de problemas músculoesqueléticos é bastante importante no serviço: nos anos de 2001 e 2002 houve 7 no total de 13 casos na Agência, sendo que os servidores do setor representavam um quarto $(25 \%)$ do total de servidores. Além disso, havia prevalência importante de casos de distúrbios do comportamento (relatados informalmente). 
Os problemas de funcionamento do setor refletiam sua "má fama"; muitos servidores expressaram sua intenção de deixar o setor ou a Agência. Alguns indicadores, relativos às características do grupo de servidores, confirmavam a situação: os servidores possuíam média de idade, 33,9 anos, bem inferior à dos demais da AGPC, 38,5 anos, e menor média de tempo de serviço, 4 anos contra 6,3 anos do total de servidores.

A rotatividade dos servidores também foi importante no período. A título de exemplo, no ano de 2001, do total de 19 servidores, três servidores deixaram a Agência e dois se transferiram para outros setores.

\section{Retrabalho e erros freqüentes}

A grande contradição do funcionamento - o retrabalho existente - era visível durante curtos períodos de observação: reuniões eram marcadas, canceladas e remarcadas, documentos eram refeitos freqüentemente, dentre outros problemas.

As causas do retrabalho eram variadas: a falta de comunicação entre AEs, as trocas de AEs na DDD, dificuldade de relação entre AEs e servidores, falta de entendimento das ordens escritas, "erros", e, sobretudo, a inexistência de formas preventivas de "controle da qualidade".

Os erros dos servidores eram objeto da preocupação dos AEs nas reuniões do colegiado. Eram, de certa forma, conseqüência natural do sistema de funcionamento, devido à grande quantidade de tarefas a realizar, à natureza das tarefas e à inexistência de meios para conferi-las, à "pressão" de alguns AEs, ao espaço insuficiente e à falta de equipamentos.

\section{Crise de relações}

As relações no setor eram difíceis, devido, em parte, à postura coercitiva de determinados AEs e à busca de responsabilização pelos "erros" e pelos problemas de funcionamento.

Grave crise ocorreu entre servidores que ocupavam cargo de nível superior e os demais servidores, quando os primeiros se mobilizaram para influenciar a criação de nova estrutura organizacional que lhes reservasse apenas tarefas de nível superior.

Paralelamente, as relações entre os próprios AEs eram tensas em determinadas situações. A divisão da grande quantidade de trabalho e os problemas de funcionamento do Setor de Apoio, por serem temas de difícil solução de consenso, tornavam as reuniões de coordenação em espaços de muitos conflitos.

\section{Limitações do funcionamento}

Não havia servidores disponíveis para acompanhar os AEs nas inspeções de campo, atividade fundamental para a eficácia de determinadas ações da DDD. Constituía-se, assim, como gargalo para certos procedimentos.

Embora estudos visando conhecer os fluxos existentes, os volumes, os gargalos, as durações médias, entre operações e procedimentos completos, não tivessem sido realizados, suspeitava-se que a duração entre operações e procedimentos era muito longa.

A organização vigente à época podia ser considerada como impeditiva ao desenvolvimento intelectual dos servidores. Por outro lado, era um modo que aumentava a rigidez de funcionamento do sistema e, nesse sentido, as próprias atividades dos AEs estavam se reduzindo às possibilidades e à capacidade de atendimento do setor.

\section{Do processo social de desenho do trabalho e da organização}

Antes de descrever o processo social, apresentaremos de forma sumária algumas características da evolução dos modos de organização de 1997 a 2003.

\section{As características da evolução da organização}

A evolução dos modos de organização foi "puxada" pelo aumento da demanda social. No entanto, diante do processo social de desenho do trabalho existente, ela teve as seguintes características:

- Houve a realocação dos "recursos humanos" disponíveis, isto é, servidores com cargo de nível superior passaram a executar tarefas que normalmente seriam atribuídas a apenas servidores com cargo de nível médio, para atender e tratar da demanda imediata.

- A organização da DDD passou de modo de grande flexibilidade - atendimento personalizado aos AEs - para modo rígido, no qual a liberdade de ação dos AEs deveria conformar-se às regras de funcionamento do setor.

- Não foram utilizados parâmetros de funcionamento do sistema (volumes, fluxos, gargalos, tempos, etc.) como determinantes para o redesenho organizacional. A reorganização reduzia-se praticamente a nova redistribuição de tarefas.

- O processo de mudança organizacional não foi participativo, tendo sido conduzido pela equipe de coordenação dos AEs com a colaboração eventual da servidorachefe do Setor de Apoio.

\section{Legitimidade e competência}

\section{para desenhar a organização}

Os redesenhos do trabalho e da organização foram feitos por coordenações distintas, que se sucederam na DDD. Tais mudanças tiveram como objetivo central adequar a capacidade de atendimento à demanda da sociedade. Mas, diante da insuficiência dos modos de organização adotados, as mudanças não permitiram no longo prazo atender às necessidades da divisão: erros proliferaram, 
retrabalho não pôde ser controlado e evitado, e algumas atividades tornaram-se gargalos para o sistema.

Os AEs tinham competência requerida na "tecnologia jurídica". No entanto, não possuíam competências em gestão da produção ou administração. Não possuíam, também, suporte institucional (de serviço de organização e métodos, por exemplo) para auxiliá-los no processo de mudança organizacional. O "saber-fazer" dos servidores, também, não foi colocado a serviço das mudanças organizacionais.

O centro de decisão, quanto a concursos (e à distribuição de novos servidores) e orçamento, se encontrava em Brasília. De forma sistemática, os pedidos de novos servidores feitos pela Agência não foram aceitos na quantidade necessária e na qualificação profissional (nível médio) solicitada.

Dessa forma, os AEs tiveram pouca margem de ação para influenciar o desempenho do funcionamento da Divisão por meio das mudanças da organização. Encontraram-se, como Daniellou (2000) afirmara, isto é, impotentes para reverter a situação precária do atendimento do Setor de Apoio.

Pode-se fazer a hipótese de que alguns deles também sofreram com a situação.

\section{DISCUSSÃo}

A Agência analisada, neste texto, apresenta características nítidas de organização patológica, isto é, alta prevalência de problemas músculo-esqueléticos, relações interpessoais tensas, funcionamento precário e pouca margem de ação da direção local. Viveu-se, efetivamente, uma "síndrome geral de sentimento de impotência".

Ao contrário de outros sistemas de produção ou serviço, cuja organização é projetada explicitamente para restringir e impedir as atividades das pessoas (SZNELWAR e ARBIX, 2003), o modo de organização existente foi desenhado a fim de adequar a capacidade de atendimento do Setor de Apoio ao crescimento da demanda, por meio da redistribuição das tarefas entre os servidores.

Todavia, devido à indisponibilidade de informações (qualitativas e quantitativas) a respeito da produção e dos fluxos de processos e documentos, das demandas para atuação da Agência, as "cargas de trabalho" para as diferentes tarefas não foram consideradas. A organização foi implantada restringindo as atividades dos servidores, em particular dos que tinham cargo de nível superior, limitando a atuação dos próprios AEs e da Agência.

A pouca margem de ação necessária para tomar decisões essenciais no nível local, a distância do "centro de decisão central" e a dificuldade para influenciar os diretores da Agência Central, quanto ao ingresso de novos servidores ou para obter meios mais adequados de trabalho (equipamentos, espaço, etc.), também, determinaram o modo de organização adotado.

Esses diferentes aspectos - a distância da instância central de tomada de decisões, a falta de serviços de desenho do trabalho e da organização, a fragilidade (ou até inexistência) de instrumentos de gestão adequados, a pequena margem de ação da gestão no nível local podem ser analogamente encontrados em outras instituições públicas do país (JACKSON e BARCELOS, 1999), o que explicaria, em parte, a precariedade de funcionamento no setor público.

\section{- ncontraram-se, como Daniellou (2000) afirmara, isto é, impotentes para reverter a situação precária do atendimento de Apoio.}

De modo geral, a noção de patologia organizacional indica crise no desenho do trabalho e da organização que, embora não seja exclusiva ao setor público, reflete, neste setor, o desinteresse histórico dos governantes pela prestação de serviços para a comunidade.

Para agir e transformar tais situações, é preciso influenciar os modos de desenho do trabalho, da produção ou do serviço e de sua organização. Essa ação pode e deve ser guiada pelos referenciais teórico-metodológicos da Engenharia de Produção para gerir os sistemas de produção de serviços, para projetar o trabalho e a organização e para gerir os projetos de sistemas técnico-organizacionais (SLACK et al., 1996).

Contudo, para a Engenharia de Produção, os serviços públicos constituem-se em campo, pouco conhecido, de pesquisa e intervenção. A contribuição da Engenharia de produção deve se fundamentar na apreensão do "objeto da prática" (LIMA, 1994), isto é, a produção de serviços públicos, para evitar a "utilização de modelos e princípios reducionistas, que visam antes, pragmaticamente, conformar a realidade da produção e menos compreendê-la em suas múltiplas determinações e em sua lógica imanente". (p. 74)

A Engenharia de Produção pode auxiliar, seguindo a via proposta por Lima (1994), as Instituições Públicas a romper com as práticas gerenciais, ainda fortemente influenciadas pelo taylorismo, permitindo, por que não, as condições para a participação plena dos servidores nos processos de mu- 
dança técnico-organizacionais e até na gestão dos serviços. Deve ajudar, também, as Instituições Públicas a cumprir seu papel social, favorecendo o desenho de serviços e de sistemas de gestão que considerem em primeiro plano os critérios de atendimento e respeito aos direitos dos cidadãos em detrimento da racionalidade econômica.

Enfim, para o governo atual, torna-se fundamental adotar postura mais "agressiva" para enfrentar o adoecimento dos servidores e a degradação do funcionamento dos serviços prestados aos cidadãos. A realização de concursos para a contratação de novos servidores deve ser acompanhada de medidas concretas visando conhecer o trabalho, o funcionamento existente dos serviços públicos, a demanda social e repensar e reestruturar o processo social de desenho e de gestão do trabalho nas instituições públicas. Está lançado o desafio para o atual governo brasileiro, caso o mesmo se proponha de fato a realizar os programas sociais previstos na última campanha eleitoral, e a se contrapor ao processo histórico de precarização dos serviços e de desvalorização dos seus servidores.

\title{
Artigo recebido em 10/05/2004 Aprovado para publicação em 18/12/2004
}

\author{
- Notas \\ 1. CONTATO, boletim eletrônico para \\ servidores do governo federal, n. 4 , \\ 15 de julho de 2003. \\ 2. Alguns estudos mostram a associa- \\ ção entre prevalência de problemas \\ músculo-esqueléticos e distúrbios \\ emocionais ou psíquicos [por exem- \\ plo, DOUILLET E SCHWEITZER \\ (2002)]. O próprio Daniellou (1999) \\ refere-se frequientemente ao sofri- \\ mento dos vários atores da empresa \\ ao vivenciar situações com alta \\ prevalência de problemas músculo- \\ esqueléticos. \\ 3. Após o estudo ergonômico, no- \\ vas modificações foram introduzi- \\ das na organização do setor. É im- \\ portante ressaltar que, em tais mu- \\ danças (algumas ainda em curso) \\ o móbile principal não foi a melho- \\ ria do funcionamento, mas o \\ enfrentamento dos problemas de
}

saúde dos servidores. Nota-se, dessa forma, o engajamento da direção da Agência para a resolução desses problemas, malgrado sua margem limitada de ação.

\section{- Referências Bibliográficas}

ASSUNÇÃO, A. A. De la déficience à la gestion collective du travail: les troubles musculo-squelettiques dans la restauration collective. Tese (doctorat d'Ergonomie). Paris: EPHE, 1998.

CARBALLEDA, G. Uma contribuição possível dos ergonomistas para a análise e a transformação da organização do trabalho. In: F. DUARTE (org.). Ergonomia e Projeto na Indústria de Processo Contínuo. Rio de Janeiro: Editora Lucerna, p. 281-297, 2002.

CHAUVIÈRE, M.; GODBOUT, J.T. Les usagers, entre marché et iotoyenneté. Paris: L'Harmattan, 1992.

DANIELLOU, F. Les TMS, symptôme d'une pathologie organisationnelle. BTS Newsletter, n.11/12, p. 34-37, 1999.

\section{DAUBAS-LETOURNEUX V.;} THÉBAULD-MONY A. Organisation $d u$ travail et santé dans l'Union Européenne. Dublin: Fondation Européenne pour l'Amélioration des Conditions de Travail, 2002.

DEJOURS, C. Travail: Usure mentale. Paris: Bayard. 2000.
DOUILLET, P.; SCHWEITZER, J.M. TMS, stress: gagner des marges de manoeuvre. BTS Newsletter, n. 19-20, p. 64-66, 2002.

DUARTE, F. (Org.). Ergonomia e Projeto na Indústria de Processo Contínuo. Rio de Janeiro: Editora Lucerna.

HAMON-CHOLET S.; ROUGEREIE C. La charge mentale au travail: des enjeux complexes pour les salaries. Economie et statistique, v. 339/340, p. 243-255, 2000.

GUÉRIN, F.; LAVILLE A.; DANIELLOU, F.; DURAFFOURG, J.; KERGUELEN A. Compreender o trabalho para transformálo. São Paulo: Edgar Blücher, 2001.

JACKSON, J.M.; BARCELOS, M.A. Entre a qualidade na promoção à saúde e a manutenção da própria saúde: as contradições do trabalho das agentes comunitárias de saúde do Posto de Saúde do Boehmerwaldt - Programa de Saúde da Família, Joinville. Relatório de pesquisa. Florianópolis: FUNDACENTRO/SC, 1999.

LIM, S.-Y.; SAUTER, S. T.; SWANSON, N. G. Musculoskeletal disorders. In: STELLMAN (Ed.). Encyclopaedia of Occupational Health and Safety.

Geneva: International Labour Office. v. 2, p. 34.61-34.63, 1998.
LIMA, F.P.A. Da natureza e do objeto da engenharia de produção. Produção, v. 4, n. 1, p. 63-75, 1994.

MUNTANER, C.; EATON, W. W. Mental illness. In: STELMMAN (Ed.). Encyclopaedia of Occupational Health and Safety. Geneva: International Labour Office, v. 2, p. 34.62-34.64, 1998.

OLIVEIRA F. Privatização do público, destituição da fala e anulação da política: o totalitarismo neoliberal. In OLIVEIRA e PAOLI (Eds.). Os sentidos da democracia, políticas do dissenso hegemonia global. Petrópolis: Ed. Vozes, p. 55-81, 1999.

RAVEYRE, M.; UGHETTO, P. "On est toujours dans l'urgence" : surcroît ou défaut d'organisation dans le sentiment d'intensification du travail ? Colloque "Organisation, intensité du travail, qualité du travail", Centre d'études de l'emploi, CEPREMAP et LATTS, Paris, 21-23 novembre 2002 http//www.ce-recherche.fr/fr/ colloque.intensification/pdf/ raveyre\%20Ughetto.pdf (Visitado em 19/12/2003), 2002.

SKALEN, P. New public management reform and the construction of organizational identitites. The International Journal of Public Sector Management, v. 17 , n. 3, p. 251-263, 2003.
SLACK, A.; CHAMBERS, S.; HARLAND, CH.; HARRISON, A.; JOHNSTON R. Administração da produção. São Paulo: Atlas, 1996.

SOUZA, E.R.; MINAYO, M.C; Missão investigar. Rio de Janeiro: Garamond, 2003.

SZNELWAR, L.; ARBIX, G. Working and impediment: the causes and consequences of inadequate task content and work organization. In: Ergonomics of the digital age, Proceedings of the XVth Triennial Congress of the International Ergonomics Association (CD-ROM), august 24-29, Seoul, 2003

THEORELL, T.; JOHSON, J.V. Cardiovascular diseases. In STELMMAN (Ed.). Encyclopaedia of Occupational Health and Safety. Geneva: International Labour Office. v.2, p. 34.58-34.59, 1998.

WELLER, J.M. Stress relationnel et distance du public: de la relation de service à la relation d'aide. Sociologie du Travail, v. 44, p. 75-97, 2002.

WINKEL, J.; WESTGAARD, R.H. Ergonomic intervention research for musculoskeletal health - some future trends. Proceedings of the NES $33^{\text {rd }}$ Annual Congress. http://192.58.80.9/ org/ery/nes2001.toc.html (visitado em 19/12/2003), 2001. 